\title{
Transapical transcatheter aortic valve replacement with the balloon expandable aortic bioprosthetic valve in high risk patients with severe aortic stenosis: Intermediate-term results from the register of the clinic of cardiac surgery
}

\author{
Hulman M, Bena M, Artemiou P, Gasparovic I, Hudec V, Hasakova J \\ Medical Faculty of the Slovak Medical University, National Institute of Cardiovascular diseases, \\ Clinic of Cardiac Surgery, Bratislava, Slovakia. ivo.gasparovic@nusch.sk
}

\begin{abstract}
BACKGROUND: The purpose of this study is to report our experience in performing transapical (TA) TAVR with a balloon-expandable valve only by cardiac surgeons, with on site interventional cardiology support.

METHODS: A retrospective review of 97 consecutive patients that underwent TA TAVR due to severe symptomatic aortic stenosis was performed from 2012 to 2016. Median follow-up time was 20.5 months. Preoperative risk factors and postoperative outcomes were evaluated using Valve Academic Research Consortium-2 definitions. RESULTS: All patients were high risk with a mean Euroscore of $7.28 \pm 7.77$. Five year and 30-day mortality were $9.3 \%$ and $1.1 \%$, respectively. Ninty six (98.9\%) of the patients had no or mild paravalvular leak seen by transesophageal echocardiography after implantation. Device success was $91.8 \%$. Postoperatively there was a significant increase of the ejection fraction $(50.8 \pm 7.1 \%$ preoperatively vs $53.1 \pm 7.7 \%$ postoperatively, $p=0.009)$ and reverse remodeling of the left ventricle (left ventricular end-diastolic diameter preoperatively $50.8 \pm 7.1 \mathrm{~mm}$ vs $49.2 \pm 8.1 \mathrm{~mm}$ postoperatively, $\mathrm{p}=0.031$ ).

CONCLUSION: Our experience demonstrates that TA TAVR can be performed only by cardiac surgeons, with on site interventional cardiology support safely and successfully with low and comparable postoperative mortality and rate of complications (Tab. 4, Fig. 1, Ref. 26). Text in PDF www.elis.sk.

KEY WORDS: transapical TAVR, interdisciplinary heart team.
\end{abstract}

\section{Introduction}

Transcatheter aortic valve replacement (TAVR) has become a dominant topic in the field of cardiac surgery and cardiology over the last few years. TAVR has enabled treatment of severe aortic stenosis in inoperable and high-risk surgical aortic valve replacement candidates (1-4). This new approach has also led to the formation of heart teams at many cardiovascular centers which were established in the new guidelines (5).

The most commonly performed method of access is the transfemoral (TF) approach. However, there is a subset of patients for whom transfemoral access is not possible because of size, tortuosity, or calcification of the femoral vessel. In response, alternative access routes have been developed such as the transapical (TA) approach.

Medical Faculty of the Slovak Medical University, National Institute of Cardiovascular diseases, Clinic of Cardiac Surgery, Bratislava, Slovakia.

Address for correspondence: I. Gasparovic, MD, National Institute of Cardiovascular Diseases, Pod Krasnou horkou 1, SK-831 01 Bratislava, Slovakia.

Phone: +421.915919191, Fax: +421.2.59320287
In our institute, from the beginning of 2013 TA TAVR procedures are performed only by cardiac surgeons with a stand-by invasive cardiologist that can be called without time delay in case of emergency.

We report our experience and 5 years results performing TAVR using the transapical approach

\section{Patients and methods}

\section{Patients}

The TAVR program in our institute has started in October 2012 and by the end of December included 97 transapical and 9 transaortic TAVR. During the first few transapical TAVR implantations an invasive cardiologist was a part of the interdisciplinary team that performed the procedures, but with time and by gaining experience by the cardiac surgeons with the transcatheter techniques, from January 2013 the TA TAVR procedures are performed only by cardiac surgeons with a stand-by invasive cardiologist. Also, in our institute a parallel program of TF-TAVR is running by the invasive cardiologists and during the above period 141 procedures of TF-TAVR were performed.

In this retrospective observational study only the 97 consecutive patients with severe symptomatic aortic stenosis that under- 
went TA TAVR by cardiac surgeons alone in our institute from October 2012 to December 2016 are included. The nine transaortic TAVR were all combined procedures (coronary artery revascularization or tricuspid valve annuloplasty) and are not included in the study. All patients were at high risk for conventional surgery and had additional predisposing risk factors like porcelain aorta or redo-surgery. The patients were indicated for TA TAVR by the heart team because the transfemoral access was not possible due to size, tortuosity, or calcification of the femoral vessels. Patients that were candidates for TAVR underwent a standard preoperative diagnostic work-up including transthoracic and transesophageal echocardiography, pulmonary function tests, electrocardiogram , chest X-ray and baseline blood work. Preoperative computer tomography (CT) scanning is the method of choice for annulus measurements. The study was formally approved by the institutional review board and informed consent was obtained from all patients to present it.

Every six months there was a follow-up examination with a transthoracic echocardiogram for evaluation of the aortic bioprosthetic valve. The last postoperative echocardiogram was done at the last follow-up visit. Additional information concerning mortality, morbidity and the condition of the patient were obtained by phone with patients and family members, with supplemental information being supplied by family physicians and referring cardiologists. Valve related mortality and morbidity, perioperative, 30-day, and postoperative 5 year outcomes were evaluated according to VARC2 criteria (6). The mean follow-up period was $22.55 \pm 14.2$ months (0-50 months) and the median follow-up time was 20.5 months. The follow-up was complete in $95 \%$.

\section{Surgical technique}

All the procedures were performed in a hybrid operating room under fluoroscopic and transesophageal guidance. For all patients, a temporary right ventricular epicardial pacemaker was placed. Ascending aortography was performed through the femoral artery. The patient was heparinized and maintained at an activated clotting time greater than 250 seconds.

All patients underwent transapical TAVR using the 23, 26.29 mm Sapien S3 and Sapien XT bioprosthesis (Edwards Lifesciences, Irvine, CA, USA) with the Ascendra or Centritude delivery system.

A left minithoracotomy was performed to expose the apex of the heart, after which a pericardial well was created and double purse-string sutures were placed on the apex. The left ventricle was accessed and a guidewire was inserted across the stenotic valve. A pigtail catheter was placed in the sinus of Valsalva through the right femoral artery to inject the contrast medium. It is was also used to facilitate valve positioning and deployment as well as for the final angiogram and coronary angiography.

After introducing the Ascendra or the Centritude delivery system through a $18 \mathrm{~F}$ sheath, balloon valvuloplasty was performed under rapid pacing (180/min) to obtain a systolic pressure of $50 \mathrm{mmHg}$. The Edwards Sapien S3 and XT valves were introduced through the delivery system across the aortic valve in an antegrade fashion and then carefully positioned and deployed under rapid pacing. Finally, the guidewire was removed, and the double purse-string sutures were tied down securely under rapid ventricular pacing.

\section{Statistical analysis}

All variables were expressed as mean+/- standard deviation, median and interquartile range, and qualitative variables as numbers and percentages. A paired two-tailed t-test probability was used to compare the preoperative variables as well as the postoperative variables. The Kaplan-Meier survival curve analysis was performed with the Greenwood formula of variance. A p value of less than 0.05 was considered statistically significant. The statistical analyses were performed using the XL STAT 2016 (New York, N, USA).

\section{Results}

In the period from October 2012 to December 2016 a total of 97 patients with severe aortic stenosis were treated with the transapical TAVR procedure. All of these patients belonged to a typical

Tab. 1. Preoperative demographic and clinical characteristics.

\begin{tabular}{|c|c|}
\hline Variable & $\mathrm{n}=97$ \\
\hline Age, mean \pm SD, median (IQR 25-75\%), years & $77.3 \pm 8.5,79.2(74.3-83)$ \\
\hline Female, n (\%) & $48(47.5 \%)$ \\
\hline Body mass index, mean \pm SD, median (IQR 25-75\%) & $28 \pm 4.5,28.2(24.8-30.5)$ \\
\hline Cerebrovascular disease, $\mathrm{n}(\%)$ & $35(36 \%)$ \\
\hline Diabetes mellitus, n (\%) & $42(43.2 \%)$ \\
\hline Chronic obstructive pulmonary disease, n (\%) & $41(42 \%)$ \\
\hline Peripheral vascular disease, $\mathrm{n}(\%)$ & $40(41 \%)$ \\
\hline Ischemic heart disease, $n(\%)$ & $54(55.7 \%)$ \\
\hline Myocardial infarction, $\mathrm{n}(\%)$ & $28(28.9 \%)$ \\
\hline Previous PCI, n (\%) & $11(11.3 \%)$ \\
\hline Previous CABG, n (\%) & $13(13.4 \%)$ \\
\hline Previous valve procedure, n (\%) & $1(1.1 \%)$ \\
\hline Previous pacemaker implantation, n (\%) & $1(1.1 \%)$ \\
\hline Atrial fibrillation, n (\%) & $26(26.8 \%)$ \\
\hline Paroxysmal & $11(11.3 \%)$ \\
\hline Persistent & $2(2.1 \%)$ \\
\hline Permanent & $13(13.4 \%)$ \\
\hline Euroscore, mean \pm SD, median, (IQR 25-75\%) & $7.28 \pm 7.77,5.3(4-8.2)$ \\
\hline NYHA class III or IV, $\mathrm{n}(\%)$ & $92(94.8 \%)$ \\
\hline Porcelain aorta, n (\%) & $86(88.7 \%)$ \\
\hline Ejection fraction, mean \pm SD, median, (IQR 25-75\%), \% & $50.5 \pm 10.7,53(45-60)$ \\
\hline Aortic valve regurgitation, $\mathrm{n}(\%)$ & $79(81.4 \%)$ \\
\hline Grade 1, n (\%) & $70(72.2 \%)$ \\
\hline Grade 2, n (\%) & $9(9.3 \%)$ \\
\hline Mitral valve regurgitation, $\mathrm{n}(\%)$ & $77(79.3 \%)$ \\
\hline Grade $1, \mathrm{n}(\%)$ & $50(51.5 \%)$ \\
\hline Grade 2, n (\%) & $25(25.8 \%)$ \\
\hline Grade 3, n (\%) & $2(2.1 \%)$ \\
\hline Tricuspid valve regurgitation, $\mathrm{n}(\%)$ & $55(56.7 \%)$ \\
\hline Grade 1, n (\%) & $36(37.1 \%)$ \\
\hline Grade 2, n (\%) & $14(14.4 \%)$ \\
\hline Grade 3, n (\%) & $5(5.2 \%)$ \\
\hline
\end{tabular}

IQR = Interquartile range, $\mathrm{PCI}$ = Percutaneous coronary intervention, $\mathrm{CABG}=$ Coronary artery bypass graft 
Tab. 2. Perioperative outcomes.

\begin{tabular}{lc}
\hline Transapical access & $97(100 \%)$ \\
\hline Valve implanted & \\
SAPIEN XT, n (\%) & $31(32 \%)$ \\
$23 \mathrm{~mm}, \mathrm{n}(\%)$ & $7(7.2 \%)$ \\
$26 \mathrm{~mm}, \mathrm{n}(\%)$ & $9(9.3 \%)$ \\
$29 \mathrm{~mm}, \mathrm{n}(\%)$ & $15(15.5 \%)$ \\
SAPIEN S3, n (\%) & $66(68 \%)$ \\
$23 \mathrm{~mm}, \mathrm{n}(\%)$ & $23(23.7 \%)$ \\
$26 \mathrm{~mm}, \mathrm{n}(\%)$ & $32(33 \%)$ \\
$29 \mathrm{~mm}, \mathrm{n}(\%)$ & $11(11.3 \%)$ \\
\hline Paravalvular leak & \\
None, n (\%) & $88(90.7 \%)$ \\
Grade 1, n (\%) & $8(8.2 \%)$ \\
Grade 2, n (\%) & $0(0 \%)$ \\
Grade 3, n (\%) & $1(1.1 \%)$ \\
\hline Transvalvular leak & \\
None, $\mathrm{n}(\%)$ & $19(19.6 \%)$ \\
Grade 1, n (\%) & $71(73.2 \%)$ \\
Grade 2, n (\%) & $7(7.6 \%)$ \\
Grade 3, n (\%) & $0(0 \%)$ \\
\hline Concomitant procedures & \\
TMVR valve-in-valve & $1(1.1 \%)$ \\
TMVR valve-in-ring & $1(1.1 \%)$ \\
TMVR valve-in-MAC & $1(1.1 \%)$ \\
\hline Valve in previous tissue valve & $2(2.1 \%)$ \\
\hline Device success, n (\%) & $89(91.8 \%)$ \\
\hline TMVR=Transcatheter mitral valve replacement, MAC $=$ Mitral annular calcification
\end{tabular}

high-risk patient cohort, with a mean age of $77.3 \pm 8.5$ years and mean Euroscore of 7.28 \pm 7.77 . The preoperative demographic and clinical characteristics are presented in Table 1.

The procedure was performed using the Edwards Sapien XT valve in 31 (32\%) patients and the Edwards Sapien S3 in 66 (68 \%) patients. Ninty six (98.9 \%) patients had no or mild paravalvular leak seen by transesophageal echocardiography after implantation. Only 1 (1.1\%) patient had a grade 3 paravalvular leak. Two patients (2.1\%) had valve-in-valve TMVR. Device success was $91.8 \%$. The perioperative outcomes are presented in Table 2.

Postoperative echocardiogram at discharge showed that there was a significant drop in mean aortic gradient (55.8 \pm 11.3 mmHg preoperatively vs $19.98 \pm 3.9 \mathrm{mmHg}$ postoperatively, $\mathrm{p}<$
Tab. 4. Postoperative, 30-day and intermediate term outcomes.

\begin{tabular}{lc}
\hline Variable & $\mathrm{n}=97$ \\
\hline Intermediate term mortality, $\mathrm{n}(\%)$ & $9(9.3 \%)$ \\
\hline Perioperative mortality, 30 day, $\mathrm{n}(\%)$ & $1(1.1 \%)$ \\
\hline Total hospitalization, mean \pm SD, median, (IQR 25-75\%), days & $9.6 \pm 5.7,7(6-8)$ \\
\hline ICU stay, mean \pm SD, median, (IQR 25-75\%) days & $5.7 \pm 5.8,4(3-5)$ \\
\hline Bleeding, re-exploration, $\mathrm{n}(\%)$ & $1(1.1 \%)$ \\
\hline Respiratory failure, $\mathrm{n}(\%)$ & $6(6.2 \%)$ \\
\hline Stroke, TIA, $\mathrm{n}(\%)$ & $4(4.1 \%)$ \\
\hline Renal injury, n (\%) & $5(5.2 \%)$ \\
\hline Wound infection, $\mathrm{n}(\%)$ & $4(4.1 \%)$ \\
\hline Redo operation due to valve failure, intermediate, $\mathrm{n}(\%)$ & $0(0 \%)$ \\
\hline Pacemaker implantation,intermediate, $\mathrm{n}(\%)$ & $5(2 \%)$ \\
\hline Paravalvular leak, intermediate & $11(11.3 \%)$ \\
$\quad$ Grade 1, $\mathrm{n}(\%)$ & $0(0 \%)$ \\
\hline Grade 2,3,4, $\mathrm{n}(\%)$ & \\
\hline IQR = Interquartile range, ICU = Intensive care unit, TIA = transitory ischemic attack
\end{tabular}

$0.05)$. Also, there was a significant increase of the ejection fraction (50.8 $\pm 7.1 \%$ preoperatively vs $53.1 \pm 7.7 \%$ postoperatively, $\mathrm{p}=0.009$ ). Moreover, there was also a reverse remodeling of the left ventricle (left ventricular end-diastolic diameter preoperatively $50.8 \pm 7.1 \mathrm{~mm}$ vs $49.2 \pm 8.1 \mathrm{~mm}$ postoperatively, $\mathrm{p}=0.031$ ). Grade 1 paravalvular leak and grade 1 aortic regurgitation were present only in 11 (11.3 \%) and 8 (8.2 \%) patients, respectively. The preoperative and postoperative (at discharge) echocardiography results are presented in Table 3.

There was 1 (1.1\%) perioperative/30-day death. The cause of death was respiratory and renal failure after the procedure. Five year mortality was $9.3 \%$ (9 patients). After discharge 3 patients died in hospice from unknown causes, and 5 patients died in hospital after readmission in peripheral hospitals from cardiac (3 patients) and respiratory (2 patients) complications. In the intermediate period only 11 (11.3\%) patients had grade 1 paravalvular leak. Also, there was no reoperation due to valve failure.

The postoperative, 30-day and intermediate term outcomes are presented in Table 4.

The 5 year mortality is presented by the Kaplan-Meier curve (Fig. 1).

Tab. 3. Preoperative and postoperative echocardiography.

\begin{tabular}{|c|c|c|c|}
\hline Variable & Preoperative & Postoperative & $\mathrm{p}$ \\
\hline Mean aortic valve gradient, mean \pm SD, median, (IQR 25-75\%), mmHg & $55.8 \pm 11.3,55(48-61)$ & $19.98 \pm 3.9,19(18-21)$ & $<0.05$ \\
\hline Aortic valve area , mean \pm SD, median, (IQR 25-75\%), $\mathrm{cm}^{2}$ & $0.64 \pm 0.14,0.60(0.56-0.70)$ & & \\
\hline Left ventricular end-diastolic diameter, mean \pm SD, median, (IQR 25-75\%), mm & $50.8 \pm 7.1,50(46-55)$ & $49.2 \pm 8.1,50(45-54)$ & 0.031 \\
\hline Ejection fraction, mean \pm SD, median (IQR 25-75\%),\% & $50.5 \pm 10.7,53(45-60)$ & $53.1 \pm 7.7,55(49-60)$ & 0.009 \\
\hline $\begin{array}{r}\text { Paravalvular leak } \\
\text { Grade 0, n (\%) } \\
\text { Grade 1, n (\%) }\end{array}$ & & $\begin{array}{l}86(88.7 \%) \\
11(11.3 \%)\end{array}$ & \\
\hline $\begin{array}{l}\text { Aortic regurgitation } \\
\text { Grade } 0, \mathrm{n}(\%) \\
\text { Grade } 1, \mathrm{n}(\%)\end{array}$ & & $\begin{array}{c}89(91.8 \%) \\
8(8.2 \%)\end{array}$ & \\
\hline
\end{tabular}

IQR = Interquartile range 
Survival distribution function

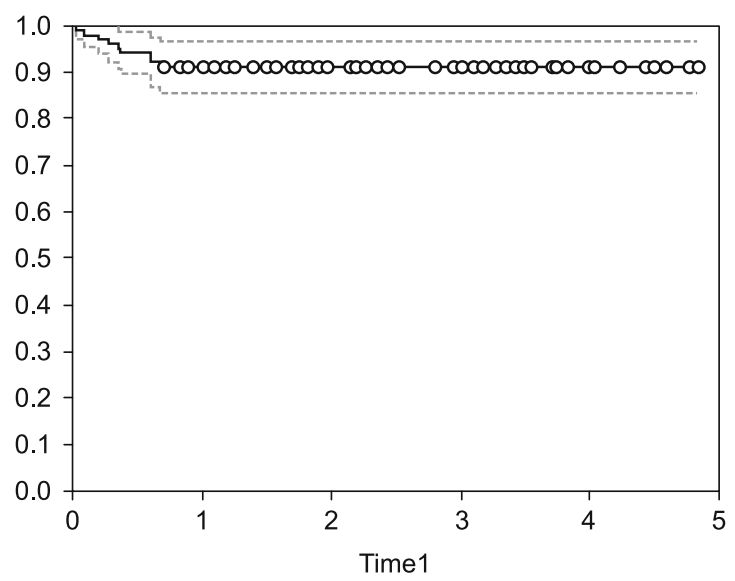

Fig. 1. 5-year Kaplan-Meier survival curve.

\section{Discussion}

The advent of TAVR has changed the management of aortic valve disease for high risk or inoperable patients for traditional surgical aortic valve replacement. Although TF TAVR may be the first option, we find that many patients are not candidates for the TF approach because of femoral vessel tortuosity, caliber or calcification. Rodes-Cabau et al (7) documented that $51.3 \%$ of 339 patients could not undergo implantation through the femoral route. The large number of patients who can potentially benefit from TAVR but cannot receive TF TAVR argues strongly for the use of alternatives approaches like the TA TAVR. All -cause 30-day mortality rates for TF TAVR have been reported to be $1.7 \%$ to $14.5 \%$, and published data thus far show that these alternative routes of access can have results similar to those in TF TAVR cohorts (8).

Invasive cardiologists are more familiar than the cardiac surgeons with the transcatheter techniques. The introduction of the TAVR led to the formation of heart teams in many centers consisting of cardiac surgeons and invasive cardiologists. The development of non-TF routes, the transapical and transaortic TAVR raised the importance of the presence of an invasive cardiologist during the valve implantation in order to assist the cardiac surgeon to perform the procedure (9-12). That was the case also in our institute. When we started the TA TAVR program in October 2012 an invasive cardiologist was a part of the team that performed the procedures. With time the cardiac surgeons became more familiar with the transcatheter techniques and gained more experience so from the beginning of 2013 the TA TAVR procedures are performed only by cardiac surgeons with a stand-by invasive cardiologist that can be called without time delay in case of emergency.

The Israeli Society of Cardiothoracic Surgery in the revised cardiothoracic surgery residency training program in Israel, after the first four years of common basic training module introduced a hybrid subspeciality program consisting of 12 months of interventional cardiology and 3 months of interventional radiology (13). Cardiac surgeons after attending such residency training program would be capable to perform transapical or transaortic TAVR procedures without the assistance of an invasive cardiologist. This is the future direction that also would change the composition and function of the heart team. With the emergence of new transcatheter procedures such as the transcatheter mitral valve replacement and paravalvular leak closure $(14,15)$ where the transapical approach is the simplest and preferred method, the training of the cardiac surgeons in the transcatheter technology becomes more timely and essential.

Another issue to be clarified is the need of a stand-by invasive cardiologist in cases where the non-TF TAVR procedure is performed only by cardiac surgeons. Coronary artery occlusion is a rare but life-threatening complication of TAVR, and this may be a reason to have an interventional cardiologist present at the operation. The incidence of this complication in subsequent TAVR series and registries has been low, nearly systematically lower than $1 \%$. It occurred more frequently in women, in patients receiving a balloon-expandable valves and the left coronary artery is the most commonly involved artery. Lower-lying coronary ostium and shallow sinus of Valsalva were associated anatomic factors. Percutaneous coronary intervention (PCI) was the preferred strategy for the treatment with a success rate of more than $80 \%$. Other options were urgent coronary artery bypass graft revascularization (CABG) and mechanical hemodynamic support. The mortality rate was high even after successful PCI (22 \%) or CABG (50 \%) and increased to as much as $100 \%$ in case of unsuccessful PCI $(16,17)$. Although, in our series of TA-TAVR we did not report this type of complication, in our institute there is always stand-by an invasive cardiologist, who in cases of emergency can be called to intervene with minimal time delay. In complicated cases, or if coronary flow is not restored within a few minutes of the attempted PCI, might be a change of the therapeutic strategy (cardiopulmonary bypass, CABG) necessary.

On the other hand, in our institute a parallel TF-TAVR program is running by the invasive cardiologists. With the same concept as before, there is an on-site cardiac surgical unit service available in order to cover for complications during and after TF-TAVR. We are in an era of increasing numbers of TF-TAVR (over $90 \%$ of the TAVR procedures) where the TA access is reserved for patients with poor vascular status as a second choice procedure $(18,19)$, and the cardiac surgeons cannot be left behind. They can be a part of the TF-TAVR as stand-by surgeons, even though they would not be directly involved in the procedure.

In this study, we reported our experience of TA TAVR performed exclusively by cardiac surgeons. Five year and 30-day mortality were $9.3 \%$ and $1.1 \%$, respectively. Our results are comparable to the others groups results where a heart team with the presence of an invasive cardiologist performed the procedures. The 30-day mortality of $1.1 \%$ was lower than in a Canadian registry (10.4 \%) (7), SOURCE (8.5 \%) (20), a FRANCE registry (12.7\%) (21), a German registry (8.2\%) (22), and the Italian registry (5.4\%) (23). A probable explanation for the higher 30day mortality with the transapical access in other centers may be the learning curve that might be prolonged with the transapical procedure. 
462-467

The 5 year mortality in our study was $9.3 \%$. Thourani et al (9) reported $7.4 \%$ and $11.7 \%$ mortality in high-risk and inoperable patients, respectively.

Post implantation paravalvular leak is believed to be an independent predictor of mortality, with increased morbidity and mortality in patients with greater than mild $(4,23)$. In our study only one (1.1\%) had grade 3 paravalvular leak. In contrast Thourani et al (9) reported a $2.2 \%$ incidence of moderate or severe paravalvular leak. Our result is comparable to the PARTNER trial, in which there was moderate or severe paravalvular aortic regurgitation in $11.8 \%$ of inoperable patients and $12.2 \%$ in high-risk patients (1, 2). At follow-up, paravalvular aortic regurgitation remained stable without significant worsening in both cohorts $(1,2)$. In our report in the intermediate term period no patient presented with moderate or severe paravalvular aortic valve leak.

We observed a significant increase in the left ventricular ejection fraction and a significant decrease in the left ventricular enddiastolic diameter after the procedure. Other authors presented similar results $(24,25)$ and our findings concur with the PARTNER trial finding that included patients with left ventricular dysfunction between $40-50 \%(1,2)$.

The postprocedural recovery of the left ventricle is not affected by the technique (transfemoral or non-transfemoral) of the TAVR but is determined by different predictors like baseline ejection function less than $35 \%(25,26)$.

The present study is limited by being observational and retrospective in nature. There is potential selection bias of patients because of the specific referral pattern to the institution and unique selection criteria of the cardiologists and surgeons. This study is also limited by the selection of patients categorized as high risk or inoperable, inherently putting this population at higher operative risk. Moreover, there is no control group (procedures when a cardiologist was involved) in order to compare the outcomes. Finally, based on our results we confirm in the conclusions the null hypothesis that outcomes are equally good with or without an interventional cardiologist as part of the heart team. This, may be questioned for potential type II statistical error due to the relatively low number of patients ( 97 patients) that took part in this study.

In conclusion, our experience demonstrates that TA TAVR can be performed only by cardiac surgeons, with on site interventional cardiology support safely and successfully with low and comparable postoperative mortality and rate of complications. We observed a significant recovery of the left ventricle after the TA TAVR.

\section{Learning points}

Transapical transcatheter aortic valve replacement can be performed safely with low postoperative morbidity and mortality in high risk patients, exclusively by cardiac surgeons with stand-by invasive cardiology support.

\section{References}

1. Leon MB, Smith CR, Mack M et al. Transcatheter aortic valve implantation for aortic stenosis in patients who cannot undergo surgery. $\mathrm{N}$ Engl J Med 2010; 363: 1597-1607.

2. Smith CR, Leon MB, Mack M et al. Transcatheter versus surgical aortic valve replacement in high-risk patients. N Engl J Med 2011; 364: 2187-2198.

3. Makkar RR, Fontanta GP,Jilaihawi $H$ et al.Transcatheter aortic valve replacement for inoperable severe aortic stenosis. N Engl J Med 2012; 366: 1696-1704.

4. Kodali SK, Williams MR, Smith CR et al. Two-years outcomes after transcatheter or surgical aortic valve replacement. N Engl J Med 2012; 366: 1686-1695.

5. Vahanian A, Iung B. The new ESC/EACTS guidelines on the managenet of valvular heart disease. Arch Cardiovasc Dis 2012; 105: 465-467.

6. Kappetein AP, Head SJ, Genereux $P$ et al. Updated standardized endpoint definitions for transcatheter aotic valve implantation: the Valve Academic Research Consortium-2 consensus document. Eur J Cardiothorc Surg 2012; 42: S45-S60.

7. Rodes-Cabau J, Webb JG, Cheung A et al. Transcatheter aortic valve implantation for the treatment of severe symptomatic aortic stenosis in patients at very high or prohibitive surgical risk. J AM Coll Cardiol 2010; 55: 1080-1090.

8. Genereux P, Head SJ, Van Mieghem NM et al. Clinical outcomes after transcatheter aortic valve replacement using valve academic research consortium definitions: a weighted meta-analysis of 3519 patients from 16 studies. J Am Coll Cardiol 2012; 59: 2317-2326.

9. Thourani VH, Li C, Devirredy C et al. High-risk patients with inoperative aortic stenosis: use of transapical, transaortic, and transcarotid techniques. Ann Thorac Surg 2015; 99: 817-825.

10. Kiefer $\mathbf{P}$, Seeburger $\mathbf{J}$, Noack $\mathbf{T}$ et al. The role of heart team in complicated transcatheter aortic valve implantation: a 7 year single-centre experience. Eur J Cardiothorac Surg 2015; 47: 1090-1097.

11. Amrane H, Porta F, van Boven AJ et al. Transcatheter aortic valve implantation using a direct aortic approach: a single-centre heart team experience. Interact Cardiovasc Thorac Surg 2014; 19: 777-781.

12. Martinez GJ, Seco M, Jaijee SK et al. Introduction of an interdisciplinary heart team- based transcatheter aortic valve implantation programme: short and mid-term outcomes. Intern Med J 2014; 44 (9): 876-883.

13. Shapira OM, Sahar G, Raanani E. Cardiothoracic training in Israel: a critical look at the past, aiming for a better future. J Thorac Cardiovasc Surg 2016; 151: 1508-1515.

14. Wilbring M, Alexiou K, Tugtekin SM et al. Pushing the limits-further evolutions of transcatheter valve procedures in the mitral position,including valve-in-valve,valve-in-ring, and valve-in-native-ring.J Thorac Cardiovasc Surg 2014; 147: 210-219.

15. Taramasso M, Maisano F, Latib A et al. Conventional surgery and transcatheter closure via surgical transapical approach for paravalvular leak repair in high risk patients: results from a single-centre experience. Eur Heart J Cardiovasc Imaging 2014; 15: 161-167.

16. Ribeiro HB, Nombela-Franco $L$, Urena $M$ et al. Coronary obstruction following transcatheter aortic valve implantation. A systemic review. J Am Coll Cardiol Intv 2013; 6: 452-461. 
17. Ribeiro HB, Webb JG, Makkar RR et al. Predictive factors, management, and clinical outcomes of coronary obstruction following transcatheter aortic valve implantation. Insights from a large multicenter registry. J Am Coll Cardiol 2013; 62: 1552-1562.

18. Landes U, Barsheshet A, Finkelstein A et al. Temporal trends in transcatheter aortic valve implantation,2008-2014; patients characteristics, procedural issues, and clinical outcome. Clin Cardiol 2017; 40 (2): 82-88.

19. Kuck K-H, Eggebrecht H, Elsasser A et al. Qualitatskriterien zur durchfuhrung der kathetergestutzten aortenklappenimplantation (TAVI). Kardiologie 2016; 10: 282-300.

20. Thomas M, Schymik G, Walther T et al. Thirdy day results of the SAPIEN aortic Bioprosthetic European Outcome (SOURCE) Registry: a European registry of transcatheter aortic valve implantation using the Edwards SAPIEN valve. Circulation 2010; 122: 62-69.

21. Eltehanimoff $\mathbf{H}$, Prat $A$, Gilard $M$ et al. FRANCE registry investigators.Transcatheter aortic valve implantation: early results of the FRANCE (French Aortic National CoreValve and Edwards) registry. Eur Heart J 2011; 32: 191-197.
22. Zahn R, Gerckens U, Grube E et al. German transcatheter aortic valve implantation: fiest results from a multi-centre real-world registry. Eur Heart J 2011; 32: 198-204.

23. Tamburino C, Capodanno D, Ramondo A et al. Incidence and predictors of early and late mortality after transcatheter aortic valve implantation in 663 patients with severe aortic stenosis. Circulation 2011; 123: 299-308.

24. Clavel MA, Webb JG, Rodes-Cabau J et al. Comparison between transcatheter and surgical prosthetic valve implantation in patients with severe aortic stenosis and reduced left ventricular ejection fraction, Circulation 2010; 122 (19): 1928-1936.

25. Dauerman HL, Reardon MJ, Popma JJ et al. Early recovery of left ventricular systolic function after CoreValve transcatheter aortic valve replacement. Circ Cardiovasc Interv 2016; 9: e00342. doi: 10.1161/CIRCINTERVENTIONS.115.003426

26. Elhmidi H, Bleiziffer S, Deutsch MA et al. Transcatheter aortic valve implantation in patients with LV dysfunction: Impact on mortality and predictors of LV recovery. J Invasive Cardiol 2014; 26 (3): 132-138.

Received January 23, 2019. Accepted April 4, 2019. 